\title{
Antibacterial and Toxicity Activities of Indonesian Herbal Medicine Extracts Used for Postpartum Treatment
}

\author{
Wiwit Denny Fitriana', Sri Banun Titi Istiqomah ${ }^{2}$, Devi Anggraini Putri ${ }^{3}$, Taslim Ersam ${ }^{4}$, Adi Setyo Purnomo ${ }^{4}$, Nurlatifah $^{4}$, \\ Sri Fatmawati ${ }^{*}$ \\ ${ }^{1}$ Faculty of Sciences and Technology, Universitas Pesantren Darul Ulum, Jombang, Indonesia \\ ${ }^{2}$ Faculty of Health, Universitas Pesantren Darul Ulum, Jombang, Indonesia \\ ${ }^{3}$ Department of Medical Laboratory Technology, Sekolah Tinggi Ilmu Kesehatan Ngudia Husada Madura, Bangkalan, Indonesia \\ ${ }^{4}$ Department of Chemistry, Faculty of Science, Institut Teknologi Sepuluh Nopember, Surabaya, Indonesia
}

\section{ARTICLE INFO}

Article history:

Received October 7, 2020

Received in revised form April 20, 2021

Accepted May 31, 2021

KEYWORDS:

antibacterial,

toxicity,

postpartum treatment,

Indonesian herbal,

$\mathrm{LD}_{50}$

\begin{abstract}
Postpartum treatments have been used by local women in Indonesia for some time now. One commonly used postpartum treatment is the consumption of a traditional herbal medicine called PHM-1 during the first 40 days after childbirth. In addition, a second medicine known as PHM-2 is taken for days 41-80. However, sufficient scientific evidence about the benefits of this postpartum herbal medicine does not exist. In this study, the antibacterial abilities of PHM-1 and PHM-2 therefore was evaluated and showed positive potential for both. Low $\mathrm{IC}_{50}$ values were obtained against pathogenic bacteria such as Escherichia coli, Staphylococcus aureus, Bacillus subtilis, Pseudomonas aeruginosa, Rhodopseudomonas palustris, Ralstonia pickettii, and Staphylococcus epidermidis and compared with chloramphenicol as a positive control. The antibacterial activity of both PHM-1 and PHM-2 against $\boldsymbol{R}$. pickettii had the highest inhibitory activity as evidenced by the lowest $\mathrm{IC}_{50}$ values of 11.16 and $6.26 \mu \mathrm{g} / \mathrm{ml}$, respectively. Furthermore, an in vivo acute toxicity test showed that PHM-1 produced a low $\mathrm{LD}_{50}$ value of $3.28 \mathrm{~g} / \mathrm{kg} \mathrm{BW}$ for both of male and female mice. These results support the use of both PHM-1 and PHM-2 as antibacterial treatments for postpartum women.
\end{abstract}

\section{Introduction}

Bacterial infections are one of the most serious postpartum clinical conditions. According to a WHO report, postpartum bacterial infections lead to over 75,000 maternal deaths worldwide (WHO 2015). These infections are experienced after both vaginal and caesarean section births. Certainly, many factors associated with postpartum infections arise from other complications, such as malnutrition, obesity, diabetes, bacterial vaginosis, and Streptococcus infections. There are many types of bacteria known to cause postpartum infections. For instance, Escherichia coli and Streptococcus equi, subspecies of zooepidemicus, have been reported to cause equine uterine disease in the early postpartum period (Dollen et al. 2019). The same postpartum uterine disease also occurred in dairy cattle (Sheldon

\footnotetext{
* Corresponding Author

E-mail Address: fatma@chem.its.ac.id

and Owens 2017) (Sheldon et al. 2009). These studies link postpartum uterine disease to E. coli, Trueperella pyogenes, Arcanobacterium pyogenes, as well as anaerobic pathogenic bacteria such as Prevotella species, Fusobacterium necrophorum, and Fusobacterium nucleatum (Sheldon and Owens 2017). Additionally, Mycoplasma hominis was responsible for an infection in a 27-year-old female patient following caesarean section (Yamaguchi et al. 2009). Staphylococcus aureus is known to be the bacterium responsible for infections resulting in acute mastitis throughout postpartum lactation periods (Rodriguez and Fernandez 2017). From these reasons, antibiotics are urgently needed to treat pathogenic bacteria during the postpartum period. Interestingly, women in Indonesia are known to consume traditional herbal medicines as postpartum antibiotic treatments.

An herbal medicine called "Jamu bersalin" is one of the folk medicines commonly used for postpartum treatment by women in Asia, especially in Indonesia (Fitriana et al. 2018) and Thailand (Panyaphu et al. 
2012). This herbal medicine is the best choice for an alternative medicine for local people in developing countries. Indonesia has abundant natural resources in which to find antioxidant, antibacterial, and antidiabetic bioactive substances. Evidence of this is scientifically based on our previous reports about an exploration of Indonesia traditional herbal medicines known for their bioactivity. For example, Chromolaena odorata is known as a potent antioxidant folk medicine in Ambon-Indonesia (Putri and Fatmawati 2019). Other natural antioxidants include Syzygium Polyanthum (Hidayati et al. 2017), Moringa oleifera (Fitriana et al. 2016), and Cajanus cajan (Ersam et al. 2016). In addition, S. polyanthum (Ramadhania et al. 2018) and Sonneratia ovate (Khumaidah et al. 2018) are reported to be antibacterial, and Garcinia mangostana is known to act as an anti-diabetic agent (Fatmawati et al. 2014). These findings support the notion that Indonesian herbal medicines might have potential for use as health supplements with low side effects in the treatment of postpartum women.

Our previous studies investigated the composition of various herbal components using a preliminary radical scavenging assay. Two postpartum herbal composition types were used, each consisting of five composition groups. The first type was Postpartum Herbal Medicine 1 (PHM-1) which was consumed by women for the first 40 days after childbirth. The second type was Postpartum Herbal Medicine 2 (PHM-2) which was consumed for the next 40 days after. The results showed that PHM-1 and PHM-2 both had the lowest inhibitory activity concentration, $50 \%\left(\mathrm{IC}_{50}\right.$ ), against DPPH and ABTS as compared to other group compositions (Fitriana et al. 2018). Hence, these results implied that PHM1 and PHM-2 compositions would provide the best use for Indonesian postpartum herbal medicines. Curcuma longa was the substance most used, which inferred that postpartum herbal medicines should contain a significant amount of $C$. longa. In support of this, many published reports assert that $C$. longa demonstrates significant pharmacological effects by being antimicrobial (Mishra et al. 2018) (Gupta et al. 2015), anti-fungal (Akter et al. 2019), anti-diabetic (Habtemariam 2019), antimalarial (Martinez-Correa et al. 2017), and anti-inflammatory (Kim et al. 2016). To this end, $C$. longa is recommended as a health supplement in postpartum treatment.

For the first time, this research aims to investigate Indonesian postpartum herbal medicines, namely
PHM-1 and PHM-2, to provide scientific evidence for their antibacterial activities. The antibacterial activity assay was performed on pathogenic Gram-positive bacteria, such as $S$. aureus, Bacillus subtilis, and Staphylococcus epidermidis, as well as Gram-negative bacteria such as E. coli, Pseudomonas aeruginosa, Rhodopseudomonas palustris, and Ralstonia pickettii.

\section{Materials and Methods}

\subsection{Material}

All of the herbal plants were collected in Jombang, East Java, in Indonesia. The composition of PHM-1 was made up of Phyllanthus urinaria (18\%), Curcuma longa (28\%), Baeckea frutescens L. (14\%), Glycyrrhiza glabra (10\%), and Anredera cordifolia (30\%). For PHM2 composition, Zingiber montamun (20\%), Zingiber zerumbet (10\%), Tamarindus indica (18\%), Quercus infectoria (24\%), and Curcuma longa (28\%) were used. Methanol and dimethyl sulfoxide (DMSO) were used as organic solvents. The antibacterial assay materials included nutrient agar (NA), nutrient broth (NB), chloramphenicol as a positive control, and a stock of bacteria including $S$. aureus, B. subtilis (NBRC 3009), E. coli (NBRC 3301), P. aeruginosa (NBRC 3080), $R$. palustris (NBRC 16661), R. pickettii (NBRC 102503), and S. epidermidis (NBRC 12993). These bacteria were collected from the Laboratory of Microbial Chemistry, ITS. For the in vivo non-clinical toxicity test, male and female mice with body weight ranges of 18-25 g were used. These mice were obtained from the Laboratory of Pharmacy, University of Indonesia.

\subsection{Preparation of Extracts}

PHM-1 (150 g) and PHM-2 (150 g) were both re-extracted using methanol $(300 \mathrm{ml})$ for 24 hours at room temperature. After the 24 hour period, the extracts were filtered using Whatman 41 filter paper. The filtrates then were evaporated using a rotary evaporator to obtain the PHM-1 and PHM-2 crude extracts.

\subsection{Antibacterial Assay}

The antibacterial activity was assayed in accordance with our previous method (Putri et al. 2018). A working solution was made from mixing 5 $\mu \mathrm{l}$ of a sample solution at a concentration of $100 \mu \mathrm{g} /$ $\mathrm{ml}$, NB media of $445 \mu \mathrm{l}$, and a bacterial suspension of $104 \mathrm{CFU} / \mathrm{ml}$, and then homogenized using a vortex. $150 \mu$ l of working solution of was then put 
into 96-micro-well plates and incubated using an incubator shaker at room temperature for 18 hours. The inhibitory activity was measured as a percentage using a microplate reader at a wavelength of $630 \mathrm{~nm}$ $\left(\mathrm{OD}_{630}\right)$. The experiment was replicated three times, using Chloramphenicol as a positive control and DMSO as a blank.

\subsection{Evaluation of In Vivo Toxicity in Mice}

The in vivo acute toxicity test was performed using parameters described in the guide book of PERKA BPOM RI No. 7/2014 on male and female mice weighing 18 to $25 \mathrm{~g}$ purchased from the Faculty of Pharmacy, at the University of Indonesia. The mice were divided into five groups; four were used for testing and one group served as a normal control. Each group of five male and female mice were given four doses dissolved with CMC $0.5 \%$. Dose amounts were $0.88,1.75,3.50$, and $7.01 \mathrm{~g} / \mathrm{kg}$ BW. Before testing, the mice fasted for 10-12 hours. After 24 hours, $\mathrm{LD}_{50}$ values were determined using the Weil formula as follows:

$$
\log m=\log D+d x(f+1)
$$

Where:

$$
\begin{array}{ll}
\mathrm{m} & =\mathrm{LD}_{50} \text { value } \\
\mathrm{D} & =\text { the smallest dose value } \\
\mathrm{d} & =\log \text { of dose } \\
\mathrm{f} & =\text { Weil table factor }
\end{array}
$$

\subsection{Statistical Analysis}

The data obtained consisted of differences between the two groups and were analysed using a one-way analysis of variance (ANOVA). The significant value was set as $\alpha=0.05$ and the graphical representation was designed by Microsoft Excel 2016.

\section{Results}

\subsection{Extraction of Postpartum Herbal Medicines (PHM)}

Two yields of crude extracts were determined, as shown in Table 1 . The yield of PHM-2 was higher than that of PHM-1. For each of the $150 \mathrm{~g}$ samples in 300 $\mathrm{ml}$ of methanol, PHM-2 yielded $23.27 \%$ extract, while PHM-1 yielded $8.82 \%$. In the present study, PHM-1 and PHM-2 made up postpartum herbal medicines with differing compositions. The exact composition was determined based on previous studies. Based on the present studies, PHM- 2 had a higher yield than PHM-1.
Table 1. The yield of postpartum herbal medicines extracts

\begin{tabular}{lcc}
\hline Herbal plants & $\begin{array}{c}\text { The composition } \\
\text { of PHM-1 }\end{array}$ & $\begin{array}{c}\text { The composition } \\
\text { of PHM-2 (g) }\end{array}$ \\
\hline P. urinaria & 27 & - \\
C. longa & 42 & 42 \\
B. frutescens L. & 21 & - \\
G. glabra & 15 & - \\
A. cordifolia & 45 & - \\
Z. montamun & - & 30 \\
Z. zerumbet & - & 15 \\
T. indica & - & 27 \\
Q. infectoria & - & 36 \\
\hline Total of weight $(\mathrm{g})$ & 150 & 150 \\
\hline Total of crude extract $(\mathrm{g})$ & 13.22 & 34.92 \\
\hline Yield $(\%)$ & 8.82 & 23.27 \\
\hline
\end{tabular}

\subsection{Antibacterial Activity of Postpartum Herbal Medicines (PHM)}

The two crude extracts' antibacterial activity was determined using a broth dilution method. The antibacterial activities are presented in Figure 1 and 2. The results showed that both PHM-1 and PHM-2 at concentrations of $100 \mu \mathrm{g} / \mathrm{ml}$ had positive inhibitory activity against E. coli, S. aureus, $B$. subtilis, P. aeruginosa, R. palustris, R. pickettii, and $S$. epidermidis, as compared with the positive control, chloramphenicol. PHM-1 was shown to be antibacterial against E. coli, S. aureus, B. subtilis, P. aeruginosa, $R$. palustris, $R$. pickettii, and S. epidermidis with $\mathrm{IC}_{50}$ values of $22.70,25.51,25.58,17.37,16.30$, 11.16, and $91.74 \mu \mathrm{g} / \mathrm{ml}$, respectively. In addition, PHM-2 showed antibacterial activity against E. coli, $S$. aureus, B. subtilis, P. aeruginosa, $R$. palustris, $R$. pickettii, and $S$. epidermidis with $\mathrm{IC}_{50}$ values of $20.51,23.70$, $20.21,19.11,11.46,6.26$, and $14.88 \mu \mathrm{g} / \mathrm{ml}$, respectively (Table 2.). Among these antibacterial activities, the antibacterial activity of both PHM-1 and PHM-2 against $R$. pickettii performed the highest in terms of inhibitory activity, as evidenced by the lowest $\mathrm{IC}_{50}$ value, indicating good antibacterial activity against $R$. pickettii for both.

\subsection{Acute Toxicity in Mice Exposed to Postpartum Herbal Medicines (PHM) In Vivo}

The in vivo acute toxicity test was performed using five groups of mice in the methodology described above. The results showed a several of deaths. After introducing the smallest to largest dose, deaths after 24 hours for male mice were $0,0,1$, and 2 , and $0,1,1$, and 2 for female mice. $\mathrm{LD}_{50}$ value was then 


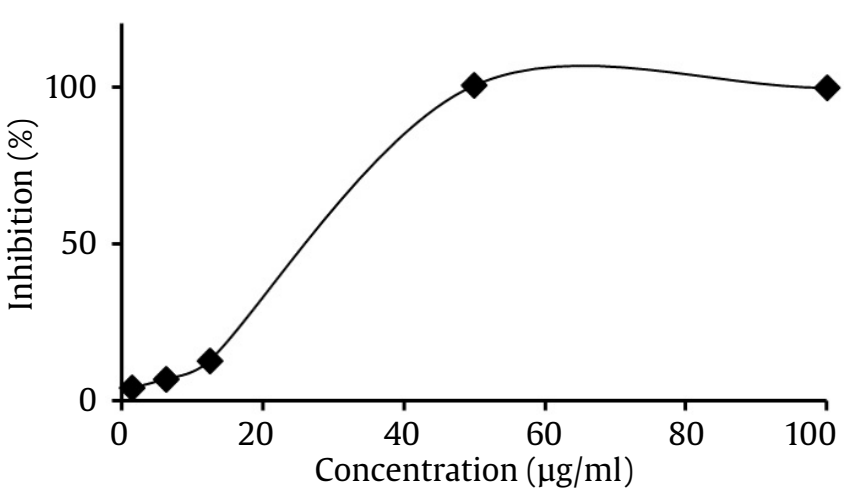

a

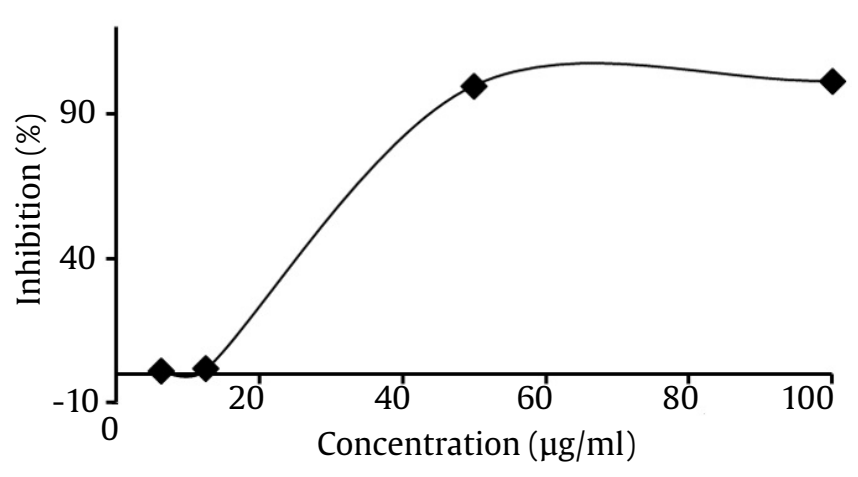

C

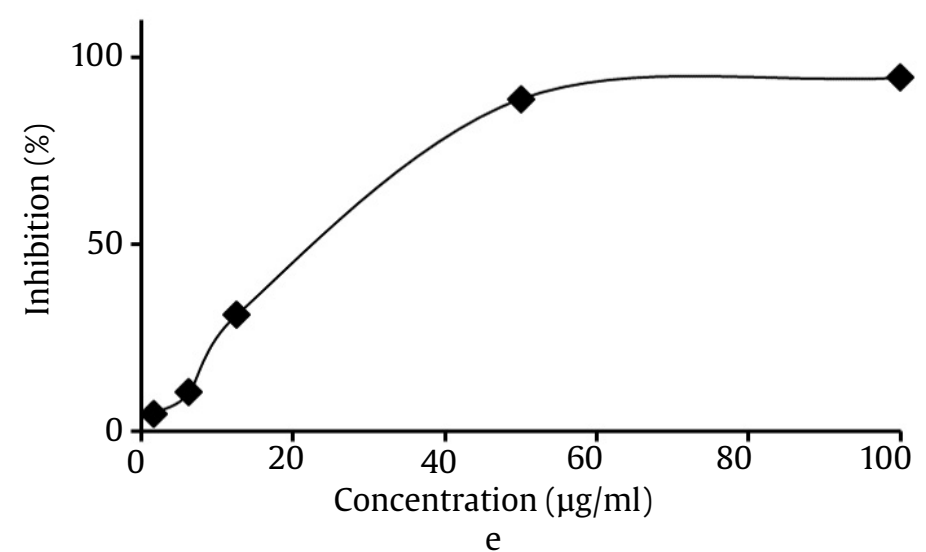

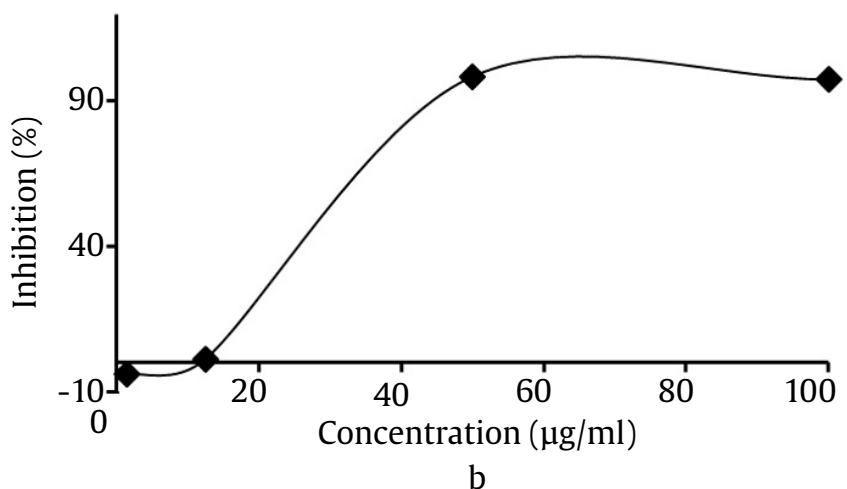

b

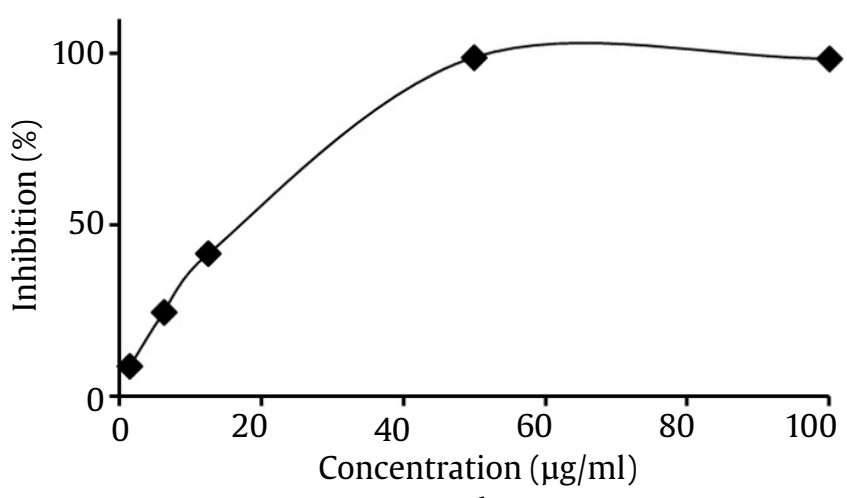

d

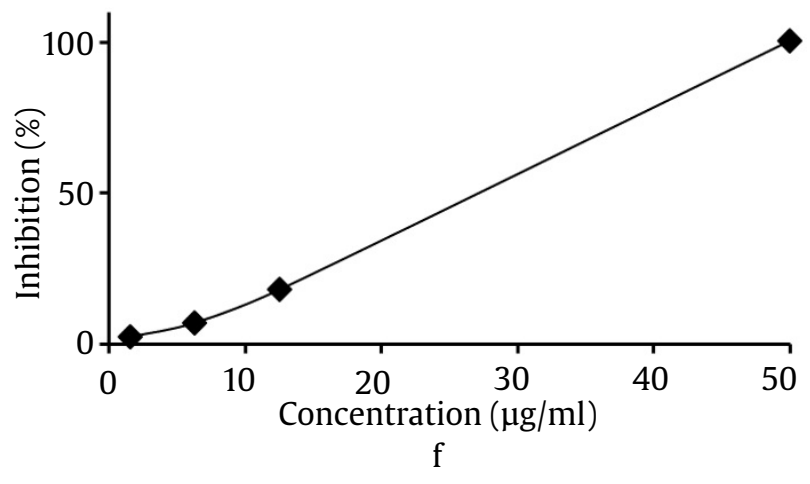

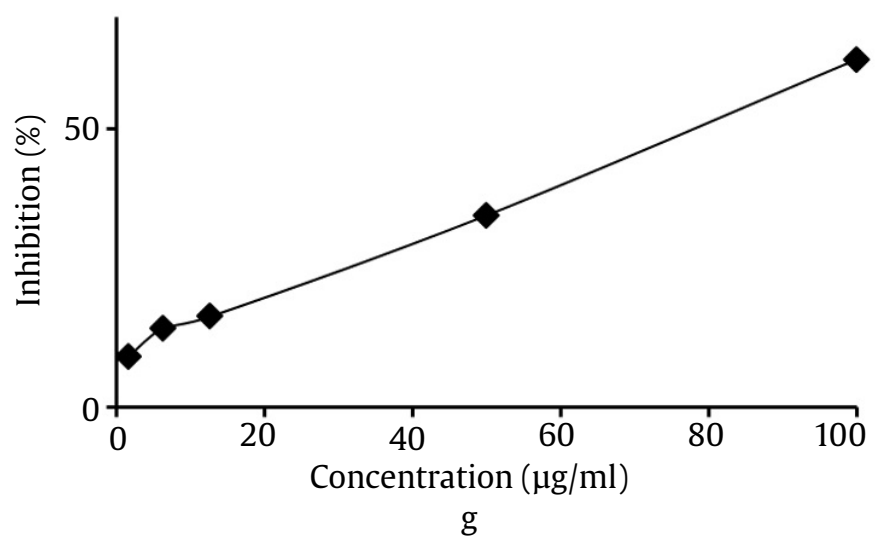

Figure 1. Antibacterial activities of PHM-1 against (a) E. coli, (b) S. aureus, (c) B. subtilis, (d) P. aeruginosa, (e) R. palustris, (f) R. pickettii, and (g) S. epidermidis 


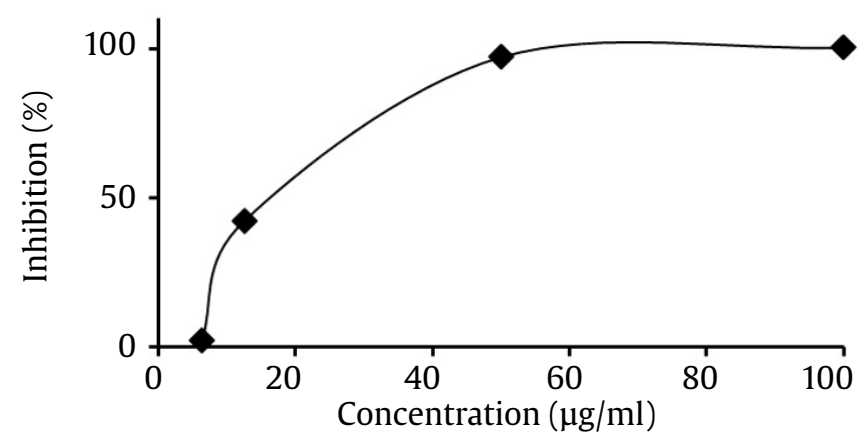

a

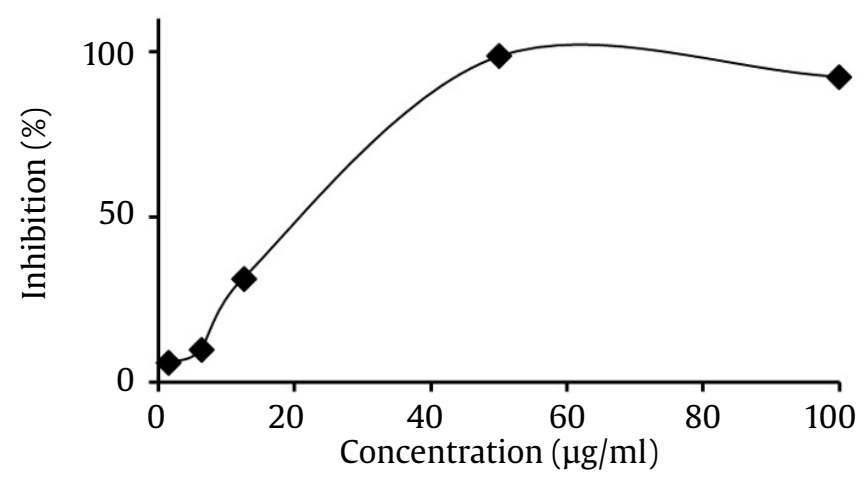

c

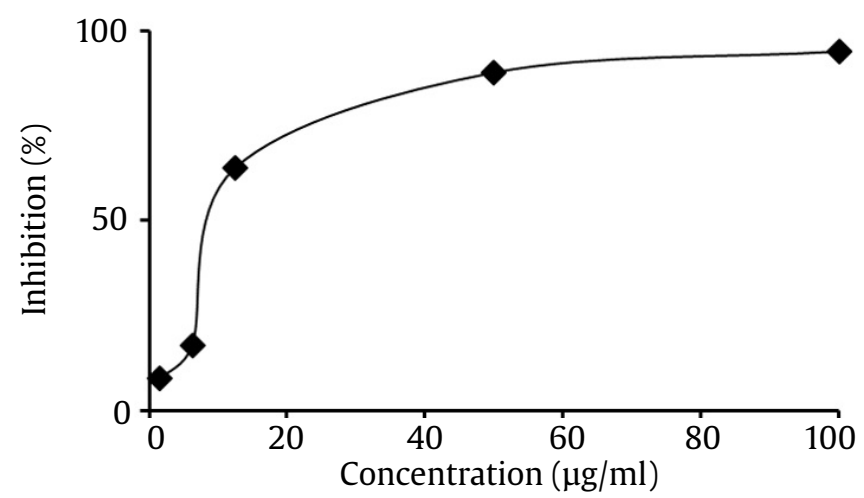

e

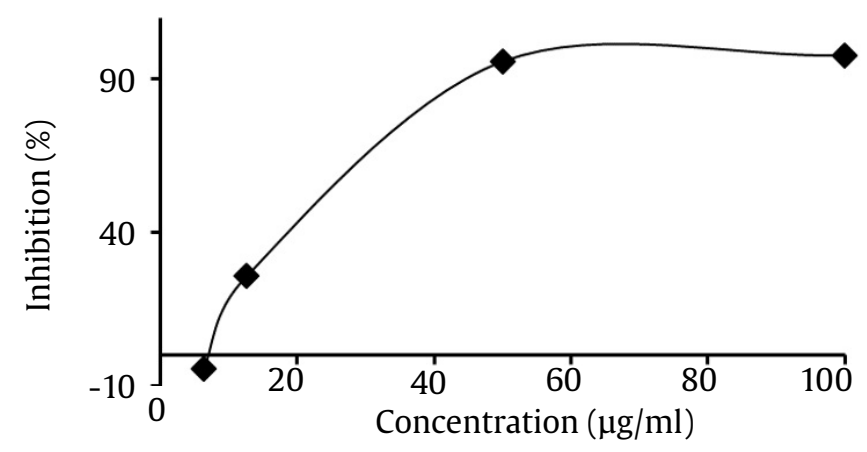

b

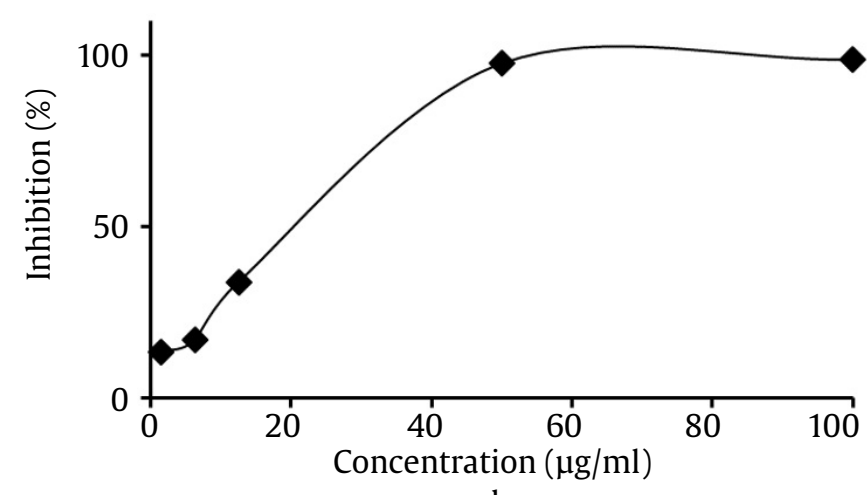

d

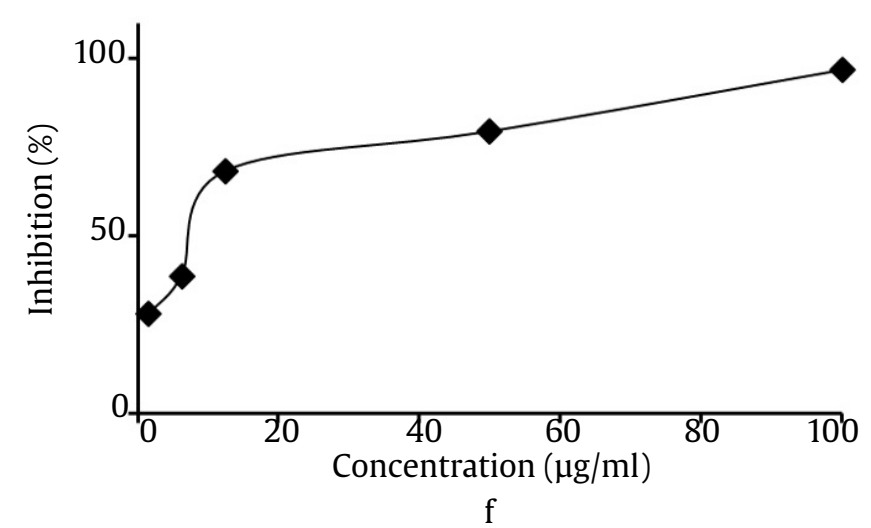

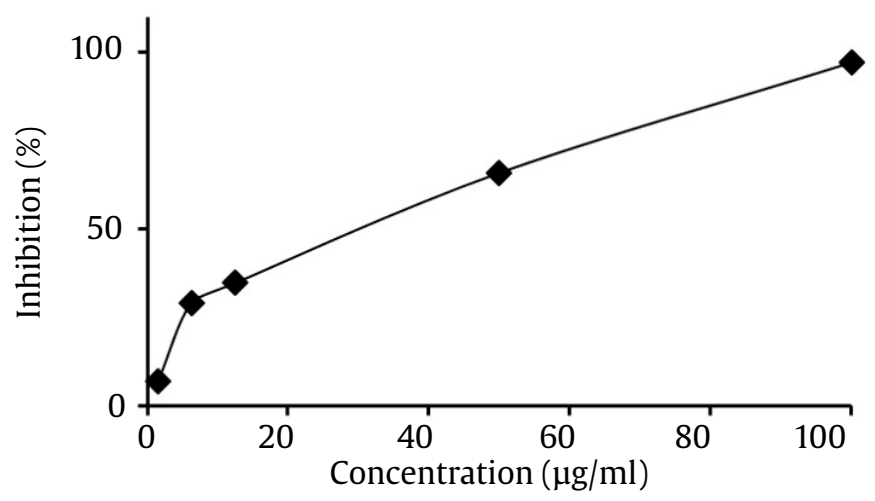

$\mathrm{g}$

Figure 2. Antibacterial activities of PHM-2 against (a) E. coli, (b) S. aureus, (c) B. subtilis, (d) P. aeruginosa, (e) R. palustris, (f) R. pickettii, and (g) S. epidermidis 
Table 2. Antibacterial activities of Indonesia postpartum herbal medicines

\begin{tabular}{|c|c|c|c|c|c|}
\hline \multirow[t]{2}{*}{ Bacteria } & \multirow{2}{*}{$\begin{array}{c}\begin{array}{c}\text { Chloramphenicol } \\
\text { (positive control) }\end{array} \\
\text { Inhibition }(\%)^{*}\end{array}$} & \multicolumn{2}{|c|}{ PHM-1 } & \multicolumn{2}{|c|}{ PHM-2 } \\
\hline & & Inhibition (\%)* & $\begin{array}{l}\mathrm{IC}_{50} \\
(\mu \mathrm{g} / \mathrm{ml})\end{array}$ & Inhibition (\%)* & $\begin{array}{l}\mathrm{IC}_{50} \\
(\mu \mathrm{g} / \mathrm{ml})\end{array}$ \\
\hline E. coli & 100.00 & 99.69 & 22.70 & 100.31 & 20.51 \\
\hline S. aureus & 98.16 & 97.41 & 25.51 & 97.89 & 23.70 \\
\hline B. subtilis & 100.00 & 101.25 & 25.58 & 92.33 & 20.21 \\
\hline P. aeruginosa & 100.00 & 98.49 & 17.37 & 98.72 & 19.11 \\
\hline R. palustris & 99.31 & 94.63 & 16.30 & 94.48 & 11.46 \\
\hline R. pickettii & 99.81 & 100.39 & 11.16 & 96.80 & 6.26 \\
\hline S. epidermidis & 100.70 & 62.47 & 91.74 & 97.18 & 14.88 \\
\hline
\end{tabular}

${ }^{*}$ Concentration samples were $100 \mu \mathrm{g} / \mathrm{ml}$

determined using the Weil formula. The $\mathrm{LD}_{50}$ value for both male and female mice was $3.28 \mathrm{~g} / \mathrm{kg}$ BW. Thus, there is a slight potential for acute toxicity in male and female mice.

\section{Discussion}

Dried powder samples of $150 \mathrm{~g}$ of PHM-1 and PHM-2 were re-extracted using methanol, as it has shown to be an effective solvent to extract all of a substance from herbal plants. In accordance with our previous studies, methanol shows the best biological activity of all extractors used, including $n$-hexane, dichloromethane, ethyl acetate, and water (Putri and Fatmawati 2019) (Hidayati et al. 2017) (Fitriana et al. 2016) (Khumaidah et al. 2018). Differences in extract yielded are known to be a result of their unique compositions. For example, PHM-2 might have a large number of chemical substances as well as secondary metabolites. Methanol is also understood to be a solvent that can extract polar compounds well. Therefore, PHM-1 and PHM-2 extract may contain polar compounds, the potential of which ought to be investigated in the next study.

Based on these results, PHM- 1 and PHM-2 both strongly inhibit Gram-positive and Gram-negative bacteria. To reiterate, E. coli and S. aureus are the Gramnegative and Gram-positive bacteria, respectively, that commonly cause postpartum infections (Dollen et al. 2019) (Rodriguez and Fernandez 2017). Generally speaking, these bacteria have different morphological structures. Gram-negative bacteria have a three-layer plasma membrane making them more complex than Gram-positive bacteria. This thicker membrane does not make it easy for chemical substance to enter the cell wall. However, PHM-1 and PHM-2 showed high percentages of inhibition against both $E$. coli and $P$. aeruginosa, compared with the positive control. Therefore, PHM-1 and PHM-2 contain bioactive chemical substances.

Interestingly, this is the first known report investigating the antibacterial effectiveness of PHM-1 and PHM-2. Our present study showed that both had high levels of inhibitory activity against $R$. pickettii, a pathogenic Gram-negative bacteria that can grow in various water sources (Ryan and Adley 2013). R. pickettii was reported to be found in several drinking and hospital water supplies, as well as in industrial-grade purity water. Furthermore, both hot and cold water is used as the main component of pharmaceutical preparation for people to consume herbal medicines. As we know, water is a vital necessity for human life. Therefore, PHM-1 and PHM2 have great potential for use as an antibacterial against $R$. pickettii. However, no sufficient data exist about the antibiotic resistance of $R$. pickettii over the course of a few decades.

Based on previously reported studies, ten plants in northern Thailand were selected for use as postpartum herbal bath medicines (Panyaphu et al. 2012). Among these plants, only two plants showed antibacterial activity against $S$. aureus strains, namely Schefflera bengalensis and Plumbago indica. However, the effect was weak, with minimum inhibitory concentration (MIC) values of 0.73 and $1.45 \mathrm{mg} / \mathrm{ml}$, respectively. In another example, $E$. coli, pathogenic bacteria widely known to cause postpartum uterine infections in equine (Dollen et al. 2019) and dairy cattle (Sheldon and Owens 2017), was not inhibited by ceftiofur. This common antibiotic is used for the early postpartum treatment of mares, and was not shown to be effective in decreasing bacterial growth of $E$. coli at a concentration of $0.5 \mu \mathrm{g} / \mathrm{ml}$ (Dollen et al. 2019). In contrast, this study successfully revealed that Indonesian herbal medicines exhibit excellent antibacterial activity. 
We also found a structure-activity relationship between the PHM substances and antibacterial activity. PHM-1 and PHM-2 both contain more $C$. longa powder than others tested. This suggests that its chemical substances might play a primary role in pathogenic bacteria inhibition. Previously, $C$. longa has been reported as an antibacterial agent working against S. aureus (Gupta et al. 2015) (Niamsa and Sittiwet 2009) and E. coli (Niamsa and Sittiwet 2009) with significant inhibitory effects. Data from this present study also support this and furthermore, indicate that the Indonesian herbal medicines PHM-1 and PHM-2 should be considered as viable antibacterial postpartum treatments for infection.

In addition, we also reported on the acute toxicity effect of PHM-1. Acute toxicity refers to the investigation of the toxic effect present from a natural or synthetic product consumed by people. This test is a crucial part of herbal medicine discovery and development related to finding safe drugs. Currently, very little information about the toxicity of some herbal medicines exists (Sharwan et al. 2015). For this reason, toxicity testing of postpartum herbal medicines is urgently needed. The toxicity test, one of several pre-clinical studies, is expressed using $L_{50}$ values. $\mathrm{LD}_{50}$ is the median lethal dose required to kill half of the mice tested. In this present study, an acute toxicity test was done by Weil method. As mentioned above, the effect of PHM-1 on both male and female mice was slightly toxic. In addition, the results showed mortality occurring after a test period of 24 hours. Consequently, autopsies were performed and showed that the size, shape, and colour of vital organs compared to the normal control group were not differently affected. Therefore, it was not necessary to continue with histological organ tests. Based on these results, herbal medicine from Indonesia can be safely consumed by women in the first 40 days of the postpartum period.

\section{Conclusion}

This was the first report on antibacterial activities of PHM-1 and PHM-2. Excellent antibacterial activity against pathogenic bacteria including $S$. aureus, B. subtilis, E. coli, $P$. aeruginosa, R. palustris, $R$. pickettii, and $S$. epidermidis was shown. In addition, acute toxicity testing indicated low risk for human consumption. In conclusion, the postpartum herbal medicines from Indonesia called PHM-1 and PHM-2 are recommended for postpartum treatment. Further research is needed to reveal the bioactive chemical substances at work and should be pursued for future study.

\section{Acknowledgements}

This research was funded by a grant from Directorate General of Higher Education, Ministry of Education and Culture, Indonesia namely research project for national research collaboration and scientific publication between universities No. 001/ K7/KM/SP2H/PENELITIAN/2019.

\section{References}

Akter J et al. 2019. Isolation and structural elucidation of antifungal compounds from Ryudai gold (Curcuma longa) against Fusarium solani sensu lato isolated from American manatee. Comparative Biochemistry and Physiology Part C: Toxicology and Pharmacology 219:87-94.

Dollen KAV et al. 2019. Antimicrobial activity of ceftiofur and penicillin with gentamicin against Escherichia coli and Streptococcus equi subspecies zooepidermicus in an Ex Vivo model of equine postpartum uterine disease. Journal of Equine Veterinary Science 79:121-126.

Ersam T et al. 2016. New prenylated stilbenes and antioxidant activities of Cajanus cajan (L.) millsp. (Pigeon pea). Indonesian Journal of Chemistry 16:151-155.

Fatmawati S et al. 2014. The inhibitory activity of aldose reductase in vitro by constituents of Garcinia mangostana Linn. Phytomedicine 22:49-51.

Fitriana WD et al. 2016. Antioxidant activity of Moringa oleifera extracts. Indonesian Journal Chemistry 16:297301.

Fitriana WD et al. 2018. The Relationship of Secondary Metabolites: A Study of Indonesian Traditional Herbal Medicine (Jamu) for Post Partum Maternal Care Use. In: The 3rd International Seminar on Chemistry. Surabaya: AIP Conference Proceedings. pp. 1-8.

Gupta A et al. 2015. Evaluation of antimicrobial activity of Curcuma longa rhizome extract against Staphylococcus aureus. Biotechnology Reports 6:51-55.

Habtemariam S. 2019. The Chemical and Pharmacological Basis of Turmeric (Curcuma longa L.) as Potential Therapy for Type 2 Diabetes and Metabolic Syndrome. In: Medicinal Foods as Potential Therapies for Type-2 Diabetes and Associated Diseases, 20 edition. Cambridge: Academic Press. pp.751-789.

Hidayati MD et al. 2017. Antioxidant activity of Syzygium polyanthum extracts. Indonesian Journal Chemistry 17:49-53.

Khumaidah L et al. 2018. In vitro antioxidant activity of Sonneratia ovata backer extract. Research Journal of Chemistry and Environment 22:146-150.

Kim DW et al. 2016. Chemical constituents and antiinflammatory activity of the aerial parts of Curcuma longa. Journal of Functional Foods 26:485-493.

Loomis TA. 1987. Essential of Toxiicology. 3rd ed. Philadelpia: Lea and Febiger.

Martinez-Correa HA et al. 2017. Composition and antimalarial activity of extracts of Curcuma longa L. obtained by a combination of extraction processes using supercritical $\mathrm{CO} 2$, ethanol and water as solvents. The Journal of Supercritical Fluids 119:122-129. 
Mishra Retal.2018.Genetic diversity, essential oil composition, and in vitro antioxidant and antimicrobial activity of Curcuma longa L. germplasm collections. Journal of Applied Research on Medicinal and Aromatic Plants 10:75-84.

Niamsa N, Sittiwet C. 2009. Antimicrobial activity of Curcuma longa aqueous extract. Journal of Pharmacology and Toxicology 4:173-177.

Panyaphu K et al. 2012. Phytochemical, antioxidant and antibacterial activities of medicinal plants used in Northern Thailand as postpartum herbal bath recipes by the Mien (Yao) community. Phytopharmacology 2:92-105.

Putri DA, Fatmawati S. 2019. A new flavanone as a potent antioxidant isolated from Chromolaena odorata L. Leaves. Evid Based Complement Alternat Med 2019:112.

Ramadhania NR et al. 2018. Antibacterial Activities of Syzygium polyanthum Wight Leaves. In: The 3rd International Seminar on Chemistry. Surabaya: AIP Conference Proceedings. pp. 1-6.

Rodriguez JM, Fernandez L. 2017. Chapter 15 - Infectious Mastitis During Lactation: A Mammary Dysbiosis Model. In: Prebiotics and Probiotics in Human Milk. Cambridge: Academic Press. pp. 401-428.
Ryan MP, Adley CC. 2013. The antibiotic susceptibility of water-based bacteria Ralstonia pickettii and Ralstonia insidiosa. Journal of Medical Microbiology 62:10251031.

Sharwan G et al. 2015. Toxicity profile of traditional herbal medicine. Journal of Ayurvedic and Herbal Medicine $1: 81-90$.

Sheldon IM et al. 2009. Defining postpartum uterine disease and the mechanisms of infection and immunity in the female reproductive tract in cattle. Biology of Reproduction 81:1025-1032.

Sheldon IM, Owens S. 2017. Postpartum uterine infection and endometritis in dairy cattle. Anim Reprod 14:622-629.

DA et al. 2018. Antioxidant and antimicrobial activities of Ananas comosus peel extracts. Malaysian Journal of Fundamental and Applied Sciences 14:307-311.

[WHO] World Health Organization. 2015. WHO recommendations for prevention and treatment of maternal peripartum infections. Switzerland: WHO Press.

Yamaguchi $\mathrm{M}$ et al. 2009. Abscess formation due to Mycoplasma hominis infection after cesarean section. J Obstet Gynaecol 35:593-596. 